\title{
Configuration Management Issues and Objectives for a Real-Time Research Flight Test Support Facility
}

Stephen Yergensen and Donald C. Rhea

(BASA-TH-100437) CCNFIGURATICA DAAGEUEAT ISSOES AND OBJECTIVES FOR A THII-IIER EESEAECH FLIGET IEST SUEPCET FACILITY (KASA) $12 \mathrm{~F}$
CSCL 12A
$188-2 C 8=2$

Unclas 0136047 


\section{Configuration Management Issues and Objectives for a Real-Time Research Flight Test Support Facility}

Stephen Yergensen and Donald C. Rhea

Ames Research Center, Dryden Flight Research Facility, Edwards, California

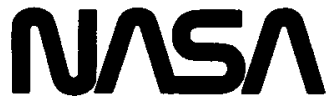

National Aeronautics and

Space Administration

Ames Research Center

Dryden Flight Research Facility

Edwards, California 93523-5000 


\title{
CONFIGURATION MANAGEMENT ISSUES AND OBJECTIVES FOR A REAL-TIME RESEARCH FLIGHT TEST SUPPORT FACILITY
}

\author{
Stephen Yergensen \\ DATAMAX Computer Systems \\ NASA Contract: NAS2-12591 \\ Lancaster, California \\ Donald C. Rhea \\ NASA Ames Research Center \\ Dryden Flight Research Facility \\ Edwards, California
}

\begin{abstract}
This paper presents some of the critical issues and objectives pertaining to configuration management (CM) for the NASA Western Aeronautical Test Range (WATR) of Ames Research Center. The primary mission of the WATR is to provide a capability for the conduct of aeronautical research flight test through realtime processing and display, tracking, and communications systems. In providing this capability, the WATR must maintain and enforce a configuration management plan (CMP) which is independent of, but complimentary to, various research flight test project configuration management systems. A primary WATR objective is the continued development of generic research light test project support capability, wherein the reliability of WATR support provided to all project users is a constant priority. Therefore, the processing of configuration change requests (CCRs) for specific research flight test project requirements must be evaluated within a perspective that maintains this primary objective.
\end{abstract}

WATR capability planners and designers must constantly endeavor to develop leading-edge system capabilities to satisfy expanding research flight test project objectives in an evolutionary manner. In conjunction with this development, the WATR must evolve and implement corresponding configuration management plans, principles, and tools so that reliability, capability integrity, maintainability, and safety criteria are ingrained within released WATR capabilities.

Research flight test project management and control decisions as well as critical real-time research mission decisions are often based on data as supplied by the WATR. Hence, the integrity and reliability of WATR supplied data and information is of the utinost importance.

\section{Nomenclature}

\begin{tabular}{|c|c|}
\hline AT & acceptance testing \\
\hline CCB & configuration control board \\
\hline CCR & configuration change request \\
\hline CI & configuration item \\
\hline CM & configuration management \\
\hline CMP & configuration management plan \\
\hline DOD & Department of Defense \\
\hline $\mathrm{DR}$ & discrepancy report \\
\hline MB & megabyte \\
\hline O\&M & operations and maintenance \\
\hline QA & quality assurance \\
\hline QSM & quality source manager \\
\hline SCM & software configuration management \\
\hline TLCMP & task life cycle management plan \\
\hline TPOC & technical point of contact \\
\hline$V \& V$ & verification and validation \\
\hline WATR & Western Aeronautical Test Range \\
\hline
\end{tabular}

\section{Introduction}

The Western Aeronautical Test Range (WATR) has experienced an almost exponential demand for increased facility capabilities. The capability of a realtime support facility to acquire data, perform real-time computations, and display the results in a readily usable and understandable form is critical to the schedule of a research vehicle program.

A key WATR configuration objective is to provide delineated, flexible, user-oriented subsystems and workstations. Research flight test project engineers can have independent interactive control of these user stations and their functional options. 
WATR subsystems and user-oriented workstations receive, or have access to, copies of first line generated WATR data. First line data is critical, process-driving data whose integrity must be safeguarded. User stations can be used for on-line research and experimentation in either simulation or real-time environments, without affecting the integrity of first line data. Providing a high degree of user flexibility and interactive control capabilities on these user stations compounds design requirements. User flexibility and interactive control capabilities, although technologically advantageous for research, introduce a significant degree of human error potential. A capability design emphasis must therefore be placed on user interaction error path response and reaction logic.

WATR subsystems and user workstations must be capable of invoking automated operational configuration controls as per research flight test project or mission requirements. That is, flexibility and interactive control capability access for any user-designated subsystem or workstation can be automatically controlled as per user configuration control requirements. The objective is to accommodate variable user research and configuration control requirements.

WATR first line data generation systems and designated critical display systems are designed to minimize human interface error potential. On-line flexibility and interactive control capabilities are not a configuration design objective on these systems. Flexibility is provided via designated setup and pre-flight systems, wherein users can pre-test and check out flight requirement specifications. WATR real-time first line data generation systems are automated so that they will not set up with unqualified flight requirement specifications for real-time operations. Automated qualification checklists are maintained by system software for individual research flight test projects.

WATR real-time first line data generation systems provide simulation and playback capabilities wherein new flight requirement specifications can become qualified for real-time operations. WATR setup and designated pre-flight systems can, in many cases (depending upon the requirement specification change), be used to qualify new flight requirement specifications.

New flight requirement specifications that excced existing WATR support capabilities can only be satisfied with the submittal of a WATR configuration change request (CCR) and its subsequent evaluation and processing. The WATR configuration control board (CCB) serves as the initial evaluation and capability release approval authority. Detailed evaluation, requirement definition, design, production, and test phase processes are conducted by designated WATR organizations.
'The WATR CCB serves as the official agent through which research flight test project officials can monitor CCR evaluation and processing status. A WATR technical point of contact (TPOC) is designated when CCR resource allocation authorization is approved by the applicable WATR organization. The TPOC collects research flight test project and user technical inputs pertinent to a specific CCR. These inputs are used in CCR engineering evaluations, and, as feasible, are incorporated into supporting designs.

The WATR endeavors to satisfy all research flight test project and user CCRs. However, the methods and processes by which these CCRs are satisfied and ultimately released for operations are an integral part of the WATR mission itself, and therefore must be independently administered via WATR configuration management policies and procedures.

This paper will detail those policies and objectives which most critically affect and apply to research flight test projects. The WATR's ability to define, develop, and administer reliable yet unobtrusive configuration management policies and procedures so that they are a valued asset, by research flight test projects and facility users, is a challenging and complex objective.

\section{Approach to Configuration Management}

Typically, organizations have about the same regard for configuration management as individuals do for taxation. They recognize that it's necessary, to some degree. Everyone, however, seems to disagree on what the levels of taxation should be, both in total and per taxable item. There is also significant disagreement as to what should and shouldn't be taxed. Everyone does seem to agree that it costs too much.

Configuration management is comprised of many supporting objectives, but above all, configuration management is a discipline concerned with the achievement of quality.

Quality is achieved by (1) engineering in quality, (2) reviewing out defects, and (3) testing out errors. There exists a lot of hand waving about what is and isn't quality. Quality requirements must be specified, just as functional requirements must be specified. Quality is an interpreted intangible only so long as it is allowed to be an intangible. A quality product is one that meets its quality specifications.

The cost of configuration management must also be weighed against costs avoided. Figure 1 shows typical relative costs of error correction at various life cycle phases. For a real-time research flight test support facility, the relative cost of error correction dur- 
ing an operations phase might be an order of magnitude higher than depicted since all research flight test projects might be impacted. Also, this does not take into account costs directly attributable to the error, which could be tragically incalculable.

Determining the appropriate degree of configuration management is critical to every organization and project. It is also controversial. Ironically, the more successful a configuration management system is, the more it is perceived as being too costly and constraining.

The process of determining and specifying configuration quality requirements is systematic. Figure 2 shows addressable quality concerns and factors.

The WATR is responsible for the development and maintenance of numerous systems, subsystems, components, and configuration items that are used by and support various research flight test projects. All WATR research flight test project support elements are delineated and identified as configuration items (CIs). A configuration item is "an aggregation of hardware/software, or any of its discrete portions, which satisfies an end use function and is designed for traceable configuration identity" (Department of Defense DIR 5010.19, DOD-STD-480).

Desired quality attributes and supporting quality specifications might vary from CI to CI. It is important to note that an emphasis on a specific quality factor might have a negative effect on another quality factor. For example, if flexibility is emphasized, it will have a negative effect on reliability. Figure 3 shows quality factor effect relationships.

Reliability is highly emphasized for most WATR CIs. WATR CIs vary significantly in reliability risk. Reliability risk determinations are made by answering the following questions:

- What are the risks if this configuration item fails to perform as expected?

- What are the risks if this configuration item fails to perform?

- What are the risks if this configuration item is inadvertently or erroneously used?

Note that these risks may vary per supported research flight test project.

Reliability risk-based configuration quality is a vital element of cost effective configuration management. For example, the testing requirements for a documentation readability analysis program simply shouldn't be as demanding as the testing requirements for a dynamic engineering units conversion compiler. Yes, it is an exaggerated example, but the point is hopefully clarified.
A noteworthy WATR CM objective is to minimize, via configuration planning, the complexity and number of configuration items which have a high reliability risk. An example follows:

At one time WATR setup software resided on first line WATR real-time systems. WATR realtime software executed as per specifications in project files generated by WATR setup software. Flight ready project files at first line WATR realtime systems could be changed inadvertently or erroneously via setup software at any time. Thus, the reliability risk of WATR setup software was quite high. Compounding this reliability risk was the fact that many times project files existed in two versions, flight ready and development. Human error potential was high.

The WATR now provides projects with a dedicated setup development system. Some of the capability and configuration management improvements are worth noting:

1. WATR setup and first line systems are configured for removable 80 megabyte (MB) project disks which can be designated flight qualified or development. These project disks are convenient for transport between setup and first line systems. Project disks also provide projects with a convenient and effective method to delineate flight qualified from development files.

2. With a dedicated setup development system, project development can parallel real-time support operations. Previously, projects were developed on first line real-time systems when they became available.

3. The dedicated setup development system can be used for postflight processing operations if first line systems are unavailable.

4. The reliability risk of WATR setup software is lower since it doesn't reside at a real-time system. Erroneous use of WATR setup software is still possible but now multiple errors must be made before real-time operations could be impacted.

5. WATR software is also contained on removable 80 MB disks. The ability to swap software systems for testing purposes is highly valuable.

Surprisingly enough, there was opposition to delineating setup and real-time systems. The drawback of having to transport $(200 \mathrm{ft}$ ) project disks from a setup system to a real-time system seemed to some to be cruel and unusual punishment. 
Configuration planning is indeed a critical function of configuration management.

The WATR mission objective of providing capabilities for the conduct of aeronautical research flight test missions mandates an emphasized quality factor of maintainability. Configuration item definitions, design, and performance requirements must be infused with maintainability criteria and considerations. The ability of the WATR to minimize system downtime is directly proportionate to its ability to achieve mission objectives.

Keep in mind that if a WATR critical system fails, then all research flight test projects will be impacted. Flight research missions will not be conducted until the failure is verifiably corrected.

Operations and maintenance (O\&M) phase CM policies and procedures are detailed later in this paper. Maintainability, however, cannot be effectively achieved unless it is considered a development priority. The way configuration items are defined and designed has a direct bearing on the WATR's ability to maintain them. Preventive maintenance commences with development planning. Figure 4 shows a quality engineering development approach.

An overview of the WATR total quality plan is presented in Fig. 5.

The last emphasized WATR CM approach we want to identify is automation. The WATR has developed automated CM tools that support and perform CM functions. Identification, configuration control, development control, status accounting, and auditing are some of the CM elements which are automatically controlled, monitored, or accounted for. The CM system, which is comprised of compatible, consistent, and logically sequenced automated CM tools, is known as our quality source manager (QSM). Figure 6 shows some of the critical QSM attributes and concepts.

The scope of WATR activities and configurations is massive and diverse. Not all activities and configurations are under QSM's watchful eye. We are convinced, however, that automated CM tools and systems can be cost effective and significantly can improve $\mathrm{CM}$ effectiveness. We hope to develop more automated CM tools.

We have identified some of the unique and emphasized WATR CM objectives and approaches. However, these described objectives and approaches are only a supporting subset of what we expect configuration management to accomplish. The following is a synopsis of expected CM accomplishments:
1. Complete control, coordination, and direction of the configuration of systems, subsystems, components, and configuration items.

2. Generation and delivery of configuration item data packages which meet functional, performance, and CM requirements.

3. An exact compliance of configuration item baselines during the various phases of a task or project.

4. A verified accounting and reporting of planned and final CIs, CI data, and configurations.

5. A systematic evaluation, coordination, approval, and implementation of changes.

6. Definition and control of interface relationships.

7. An effective liaison with research flight test projects, WATR facility users, contractors, and vendors.

\section{Operational and Maintenance Phase}

The most crucial elements of WATR CM as related to research flight test projects are the policies and procedures related to operations and maintenance (O\&M) phases of released WATR configurations. Problem-failure correction policies and procedures certainly seem to garner the most attention from research flight test projects and managers.

We will detail problem-failure correction policies and procedures as our final topic in this paper. First, we would like to present an overview of the WATR's configuration management O\&M objectives:

1. Preventive maintenance methods and procedures.

2. Maintenance of master baselines.

3. Rapid and accurate incorporation of changes.

4. Rapid and accurate dissemination of updated documentation.

5. Traceability of changes.

6. Change notification methods.

7. CCB activities.

8. Maintenance of accurate configuration identification data.

An overview of the functional flow of the change process is shown in Fig. 7. This overview includes problem-failure correction procedures. Further description of these processes follows.

WATR capabilities problems or failures are initially identified and reported via a discrepancy report (DR) form which can be filed by anyone. 
All DRs are submitted to the WATR CCB for evaluation and processing. WATR engineering and maintenance organizations will provide immediate troubleshooting support if a failure or anomaly might impact research flight test project or mission schedules. In this case DRs will be generated and submitted to the WATR CCB chairperson in parallel or immediately after troubleshooting findings.

Troubleshooting will be conducted by an assigned cognizant technical point of contact (TPOC). The TPOC will be supported by additional maintenance, operations, or engineering personnel as the TPOC deems appropriate.

The discrepancy will be demonstrated to the TPOC by a cognizant user or operator.

If the discrepancy is not reproducible, the TPOC will generate and submit a DR response report detailing reproduction attempt and evaluation methods. The WATR CCB will be responsible for determining whether or not further action is necessary.

If the discrepancy is reproducible, task and configuration item status accounts will be opened for tracking and monitoring.

The TPOC is responsible for problem isolation and "work around" options. Findings and options are to be documented in report form and submitted to the $C C B$ and the appropriate WATR engineering organization.

If "work around" options are available, the TPOC and a designated $\mathrm{CM}$ representative must generate a risk evaluation report and "work around" operational procedure documentation for submittal to the CCB.

If a "work around" option is acceptable to the CCB, then the TPOC must demonstrate the operational procedure to applicable users, research flight test project personnel, and engineering representatives.

If found to be acceptable to all concerned parties, a concurrence waiver form is to be signed by applicable users and research flight test project representatives, acknowledging acceptance of a "work around" option until final resolution.

To achieve final resolution, the following change procedures are followed:

1. Reopen the appropriate tasks for life cycle reentry at the appropriate life cycle phase. Tasks would typically be reentered at a design or production phase.

2. Formally amend design and production baselines and test plans as per task life cycle management plan (TLCMP) requirements, including all necessary reviews and submittals.
3. Baseline system testing is a delineated task which must be reopened and amended in preparation of changed configuration items.

4. Execute development baseline system testing, producing test results and reports for review, approval, and archiving.

5. Turn over system baseline to operations organization for acceptance. The turnover includes user documentation, test result and report documentation, product deliverables, installation documentation, and operation demionstrations.

6. Operations organizations will execute research flight test project acceptance tests as appropriate.

7. Formal acceptance is acknowledged by signature of operations organization, research flight test project, and WATR CCB representatives.

8. System release consists of the following:

A. Full distribution of documentation.

B. Configuration management closeout audits and reports.

C. Monitored permanent installation of product deliverables.

D. Release baseline archiving.

\section{Concluding Remarks}

Configuration management is necessary. The degree to which it is effective, advantageous, and beneficial, however, can vary significantly, depending upon approach and execution. Change control policies and procedures can become such a focused configuration management function that the overall purpose and value of configuration management is misplaced or never realized.

Configuration management is an identifiable discipline whose scope ranges from mission planning and project concepts to operations monitoring and performance trend analysis. To be ultimately effective, it must be both fully integrated into planning and development processes and yet independently accountable to delineated objectives.

\section{Bibliography}

Deutsch, M.S.: Software Verification and Validation. Prentice-Hall Inc., Englewood Cliffs, New Jersey, 1982.

Moore, A.L.: The Role of a Real-Time Flight Support Facility in Flight Research Programs. NASA TM$86805,1986$. 


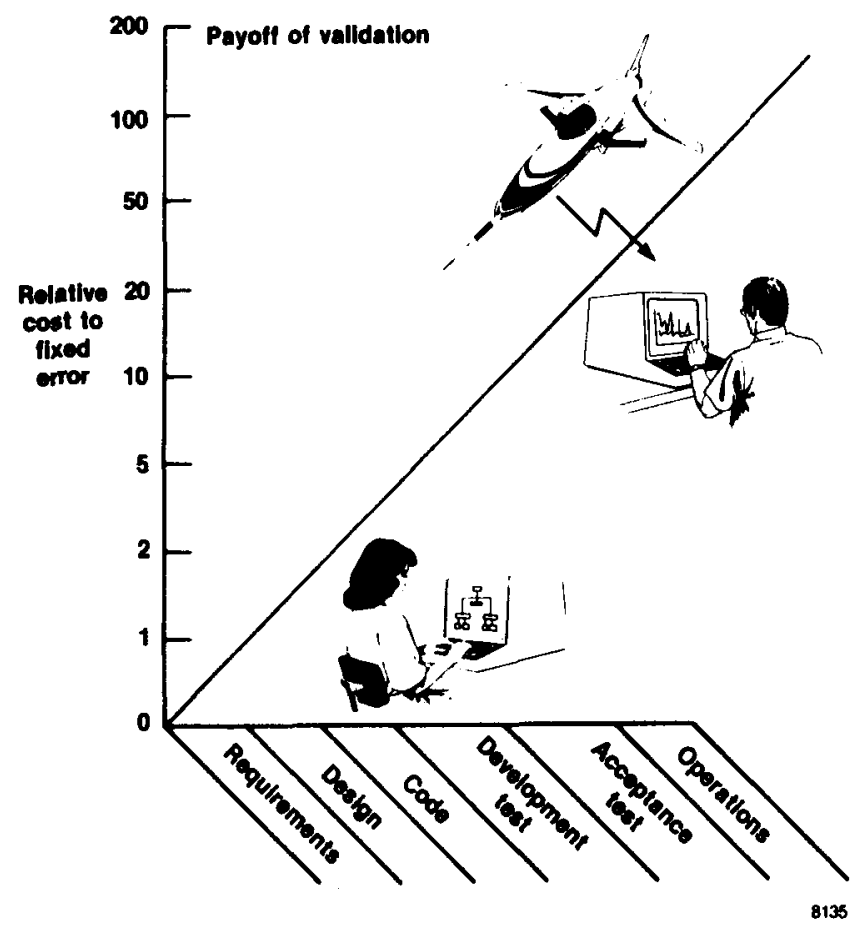

Fig. 1 Payoff of validation.

\begin{tabular}{|c|c|c|}
\hline $\begin{array}{l}\text { Acquisition } \\
\text { concern }\end{array}$ & User concern & $\begin{array}{l}\text { Quality } \\
\text { factor }\end{array}$ \\
\hline $\begin{array}{l}\text { Performance- } \\
\text { how well does } \\
\text { it function? }\end{array}$ & $\begin{array}{l}\text { - How well does it use } \\
\text { a resource? } \\
\text { - How secure is it? } \\
\text { - What conlidence can be } \\
\text { placed in what it does? } \\
\text { - How well will it perform } \\
\text { under adverse con- } \\
\text { ditions? } \\
\text { - How easy is it to use? }\end{array}$ & $\begin{array}{l}\text { Efticiency } \\
\text { Integrity } \\
\text { Reliability } \\
\text { Survivability } \\
\text { Usability }\end{array}$ \\
\hline $\begin{array}{l}\text { Design - } \\
\text { how valid is } \\
\text { the design? }\end{array}$ & $\begin{array}{l}\text { - How well does it conform } \\
\text { to the requirements? } \\
\text { - How easy is it to repair? } \\
\text { How easy is it to verify } \\
\text { its performance? }\end{array}$ & $\begin{array}{l}\text { Correctness } \\
\text { Maintainability } \\
\text { Veriflability }\end{array}$ \\
\hline $\begin{array}{l}\text { Adaptation - } \\
\text { how adaptable } \\
\text { is it? }\end{array}$ & $\begin{array}{l}\text { - How easy is it to expand } \\
\text { or upgrade its capability } \\
\text { or performance? } \\
\text { - How easy is it to change? } \\
\text { - How easy is it to interface } \\
\text { with another system? } \\
\text { - How easy is it to } \\
\text { transport? } \\
\text { - How easy is it to con- } \\
\text { vert for use in another } \\
\text { application? }\end{array}$ & $\begin{array}{c}\text { Expandability } \\
\text { Flexibility } \\
\text { Interoperability } \\
\text { Portability } \\
\text { Reusability }\end{array}$ \\
\hline
\end{tabular}

Fig. 2 Configuration quality is based on user's perception of quality. 


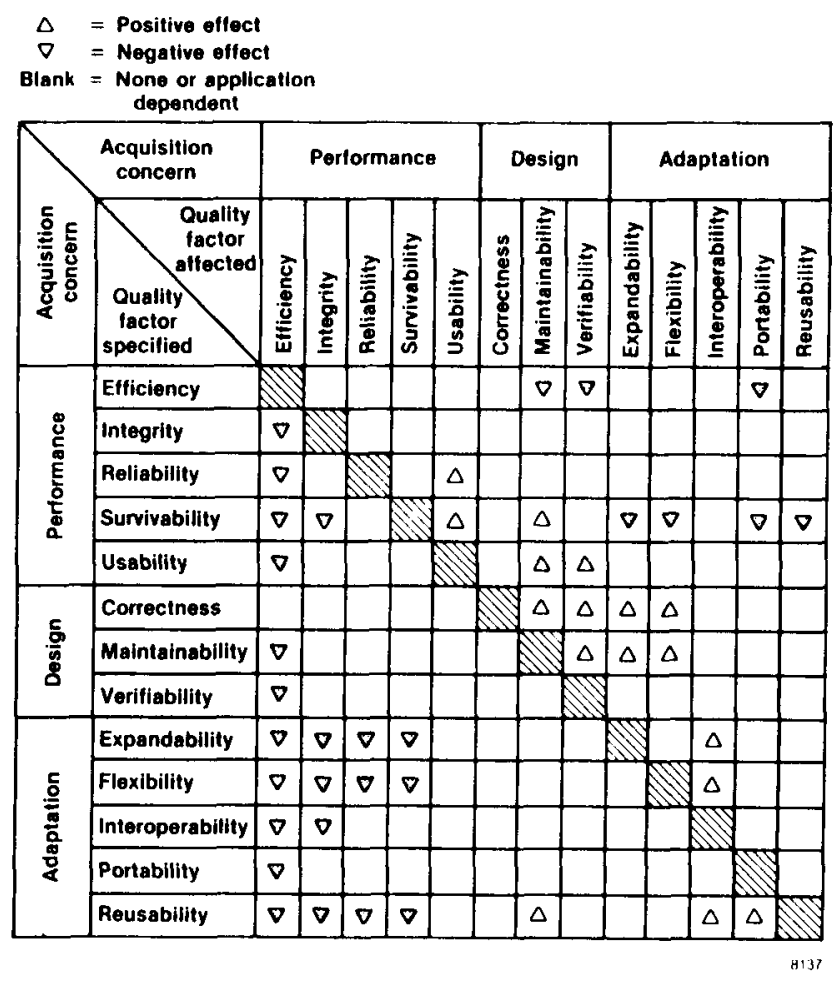

Fig. 3 All quality requirements cannot be excellent.

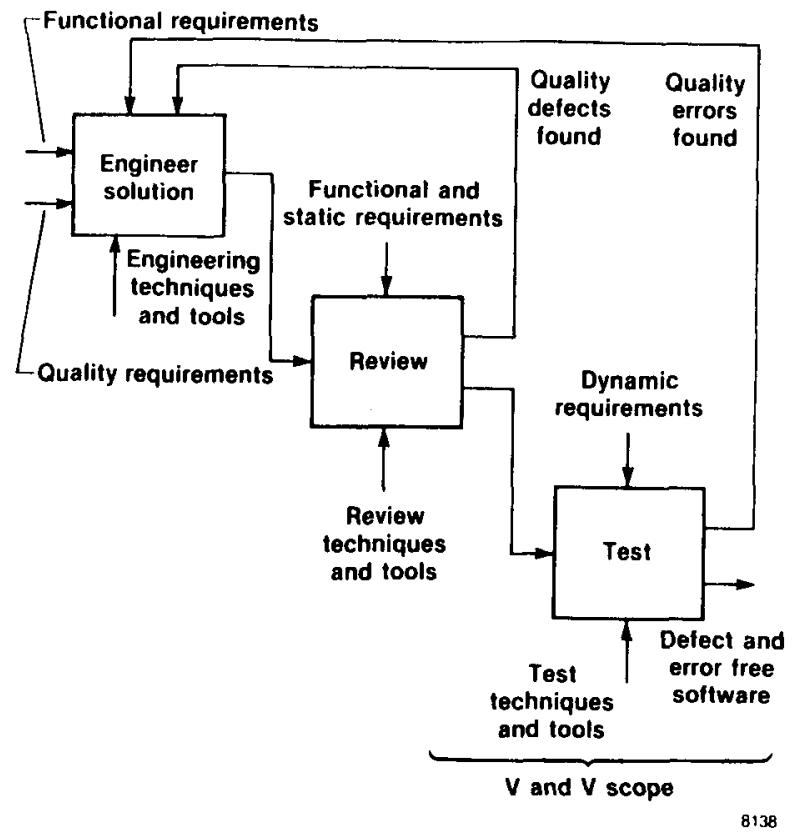

Fig. 4. Quality engineering and verification and validation. 


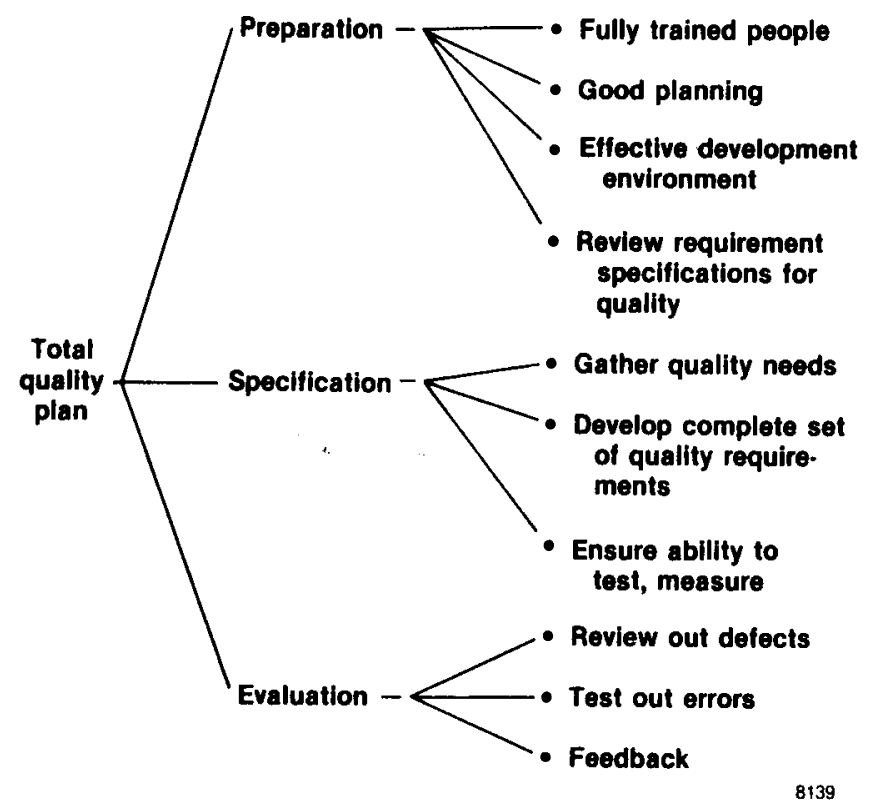

Fig. 5 Western Aeronautical Test Range quality plan overview.

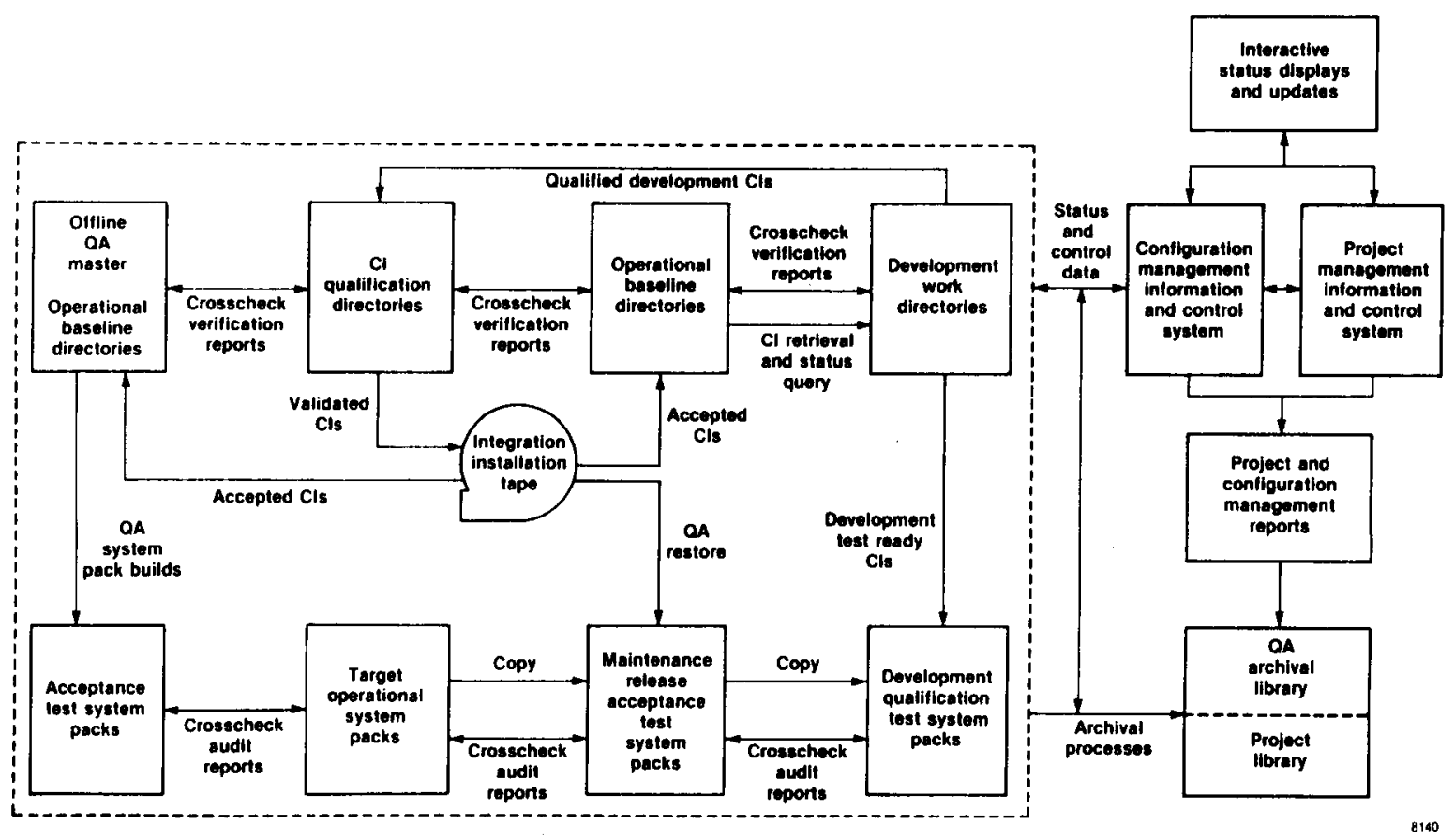

Fig. 6 Quality source manager overview, Western Aeronautical Test Range. 


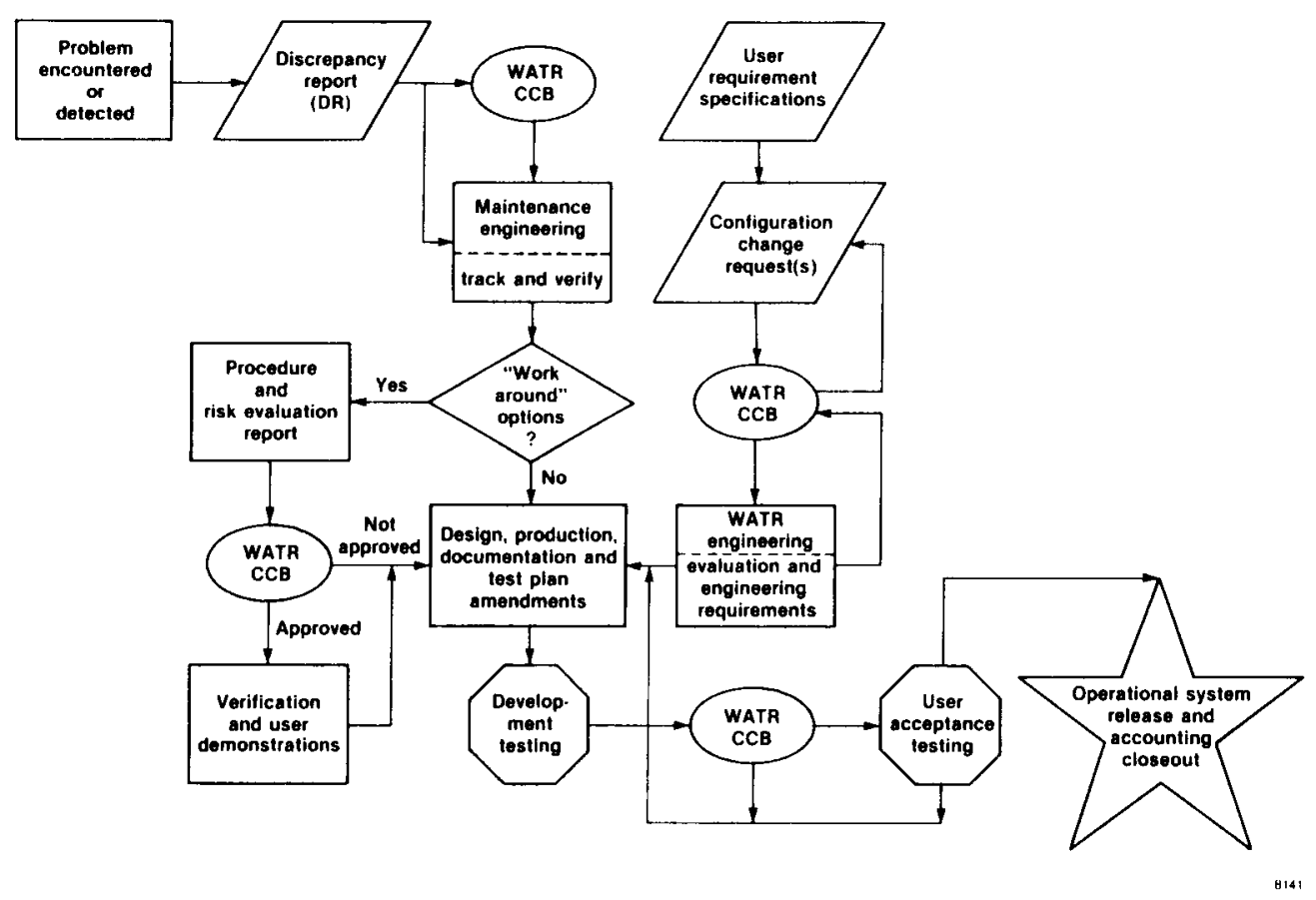

Fig. $\gamma$ Western Aeronautical Test Range change process functional flow. 


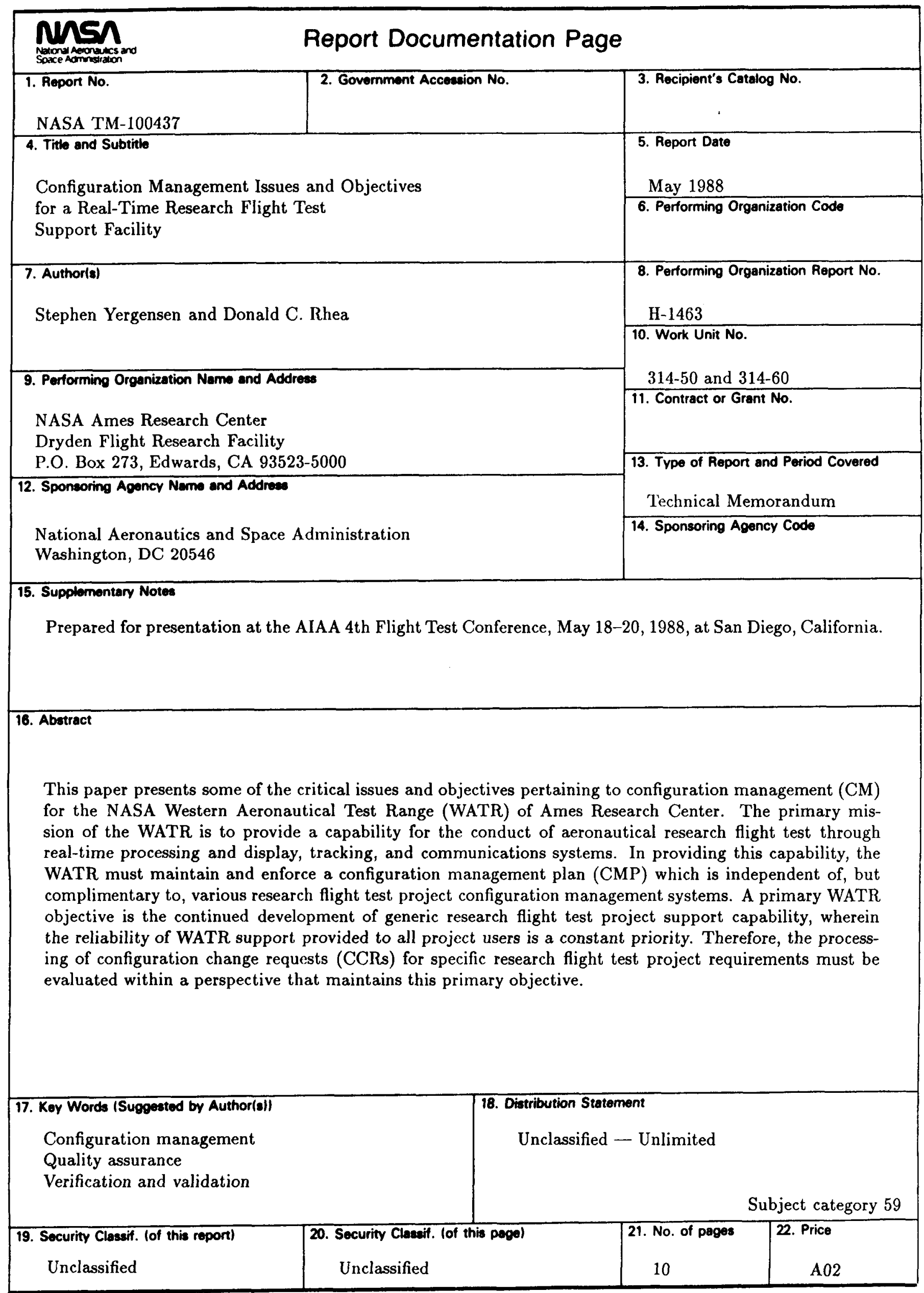

